\title{
Multiple Authorship and Article Type in Journals of Urology across the Atlantic: Trends over the Past Six Decades
}

\author{
Fayez T. Hammad ${ }^{\mathrm{a}}$ Sami Shaban $^{\mathrm{b}}$ Fikri Abu-Zidan $^{\mathrm{a}}$ \\ Departments of a Surgery and ${ }^{b}$ Medical Education, Faculty of Medicine and Health Sciences, United Arab Emirates \\ University, Al Ain, United Arab Emirates
}

\section{Key Words}

Urology journals • Multiple authorship - Type of article

\begin{abstract}
Objective: The aim of this research was to study the trends in authorship and type of article in European and North American journals of urology over the past 6 decades. Materials and Methods: Using a self-developed Visual Basic program, the number of authors per article and the type of article in four European journals (BJU International, Current Opinion in Urology, European Urology and Urologia Internationalis) and four North American journals (Journal of Urology, Urologic Clinics of North America, Urology and World Journal of Urology) were extracted from the PubMed website from January 1946 to October 2010, and the number of authors per article in each year was calculated in all the journals. Results: The average number of authors per article has increased and the percentage of single-author articles has decreased in both European and American journals. An increase in the number of authors per article was observed mainly in original articles and case reports. Since the early 1980 s, there has also been a decreasing percentage of published case reports and a general increase in the percentage of letters to the editor and editorials. Conclusions: The multiple-authorship trends observed in both European and North American urology journals were similar and appeared to be mainly due to changes in original articles and case reports.

Copyright $\odot 2012$ S. Karger AG, Basel
\end{abstract}

\section{KARGER}

Fax +4161306 1234

E-Mail karger@karger.ch

www.karger.com
C) 2012 S. Karger AG, Basel

1011-7571/12/0215-0435\$38.00/0

Accessible online at:

www.karger.com/mpp

\section{Introduction}

Since the rise of urology as an independent sub-specialty, several journals have been published solely in this field. Similar to other medical disciplines, the scientific writing in urology has undergone several changes with time. These include changes in the style of manuscript writing and the topics of interest. In other medical disciplines, it has been demonstrated that there has been an increase over time in the average number of authors per article (ANAA) and a decrease in the percentage of single-author articles (PSAA) [1-9]. In the urology literature this data is lacking. In addition, the authorship trend by the type of article is not known. Furthermore, the change over time in the type of article published has not been well documented. Obviously, the increase over time in the number of authors has affected the concept of creditaccountability associated with authorship and might indicate not only a diminishing significance of authorship but a lesser adherence to the definition of authorship in this field. It also appears to be associated with a rise in authorship disputes [10]. Therefore, identifying the trends in authorship and the type of published articles might assist in guiding the editors of urology journals and the urology community in general to follow a more scientific methodology in the definition of authorship and in determining the types of articles to be published in the future. Certainly, this would ultimately result in providing 
Table 1. Total number of articles found since the inception of the journal entries into PubMed of the European and American journals included in the study and number of authors per article

\begin{tabular}{|c|c|c|c|c|c|}
\hline Name of Journal & Years & $\begin{array}{l}\text { Total number } \\
\text { of articles }\end{array}$ & \multicolumn{3}{|c|}{ Number of authors per article } \\
\hline BJU International & $1946-2010$ & 13,312 & 3.6 & 3 & $2-5$ \\
\hline Current Opinion in Urology & $1998-2010$ & 684 & 1.9 & 2 & $1-2$ \\
\hline European Urology & $1975-2010$ & 6,198 & 4.3 & 4 & $2-6$ \\
\hline Urologic Clinics of North America & $1974-2010$ & 1,212 & 1.9 & 2 & $1-2$ \\
\hline Urology & $1973-2010$ & 14,370 & 3.9 & 3 & $2-5$ \\
\hline World Journal of Urology & 1993-2010 & 1,220 & 4.1 & 3 & $2-6$ \\
\hline
\end{tabular}

a better service to our patients. Thus, the aim of this research was to study the change with time in the ANAA and PSAA in the European and North American urology journals to determine if this change involved a particular type or all types of articles.

\section{Materials and Methods}

Journals with the following criteria were included: the country of origin (either Europe or North America) must be listed in both the PubMed and ISI Web of knowledge websites [11, 12], the journals must have a sufficient number of published articles (at least 500 articles in PubMed) and they must be published only in the English language. Exclusion criteria were journals published in other languages, sub-specialized journals and those which also address other fields such as nephrology.

Four European journals (BJU International, Current Opinion in Urology, European Urology and Urologia Internationalis) and four North American journals (Journal of Urology, Urologic Clinics of North America, Urology and World Journal of Urology) met the inclusion criteria. In a case where a journal had changed its name, all data published under the previous title were also included in the analysis. This was the case in the BJU International (previously published as British Journal of Urology).

Data collection and transformation were performed in three phases as previously described [8]. In brief, the PubMed website [11] was used to collect the data for each article in the 'Medline' form from January 1946 to October 2010. Complete data for each journal were obtained, saved as a text file on a local computer and processed using a self-developed Visual Basic program, which is a computer program used in converting the data from the PubMed format into a tubular form suitable for analysis as previously described [7]. A single-data file in tabular form was produced containing one line for each article with the following fields: name of journal, year of publication, number of authors and type of article (original article, case report, review article or letter/editorial). The above data file was then transformed into three formats suitable for regression analysis of the ANAA and PSAA for each type of article. The analysis was performed for each journal per year. The ANAA was expressed as mean \pm standard deviation and the comparison between the 1946 and 2010 ANAA was performed using the unpaired test.

\section{Results}

The number of articles found in PubMed up to October 2010 for each journal is listed in table 1. All the European journals, apart from European Urology, displayed a decrease over time in the PSAA (fig. 1) as demonstrated by the negative (downward) slope. The $\mathrm{R}^{2}$ value ranged from 0.73 to 0.83 , indicating a good fit for the linear model. In European Urology, the linear model was not good enough to explain this trend as shown by the low value of $\mathrm{R}^{2}(0.03)$. In this particular journal, there was an initial decreasing trend in the PSAA followed by an increasing trend from the year 2006 onward. Apart from the Current Opinion in Urology, the European journals demonstrated an increase in the ANAA (fig. 1) as shown by the positive (upward) slope with a very good fit for the linear model ( $\mathrm{R}^{2}$ range: 0.85-0.94). When all the European journals were grouped together the ANAA increased from $1.7 \pm 0.5$ in 1946 to $5.5 \pm 4.4$ in $2010(\mathrm{p}=0.002)$.

The American journals had a similar trend in both the PSAA and ANAA (fig. 2). The PSAA decreased over time (negative slope; $\mathrm{R}^{2}$ range: $0.58-0.76$ ). On the other hand, the ANAA in all the journals apart from the Urologic Clinics of North America increased over time (positive slope; $\mathrm{R}^{2}$ range: $0.68-0.93$ ). When all the American journals were grouped together the ANAA increased from 1.6 \pm 0.8 in 1946 to $4.8 \pm 3.2$ in $2010(\mathrm{p}=0.0001)$. 


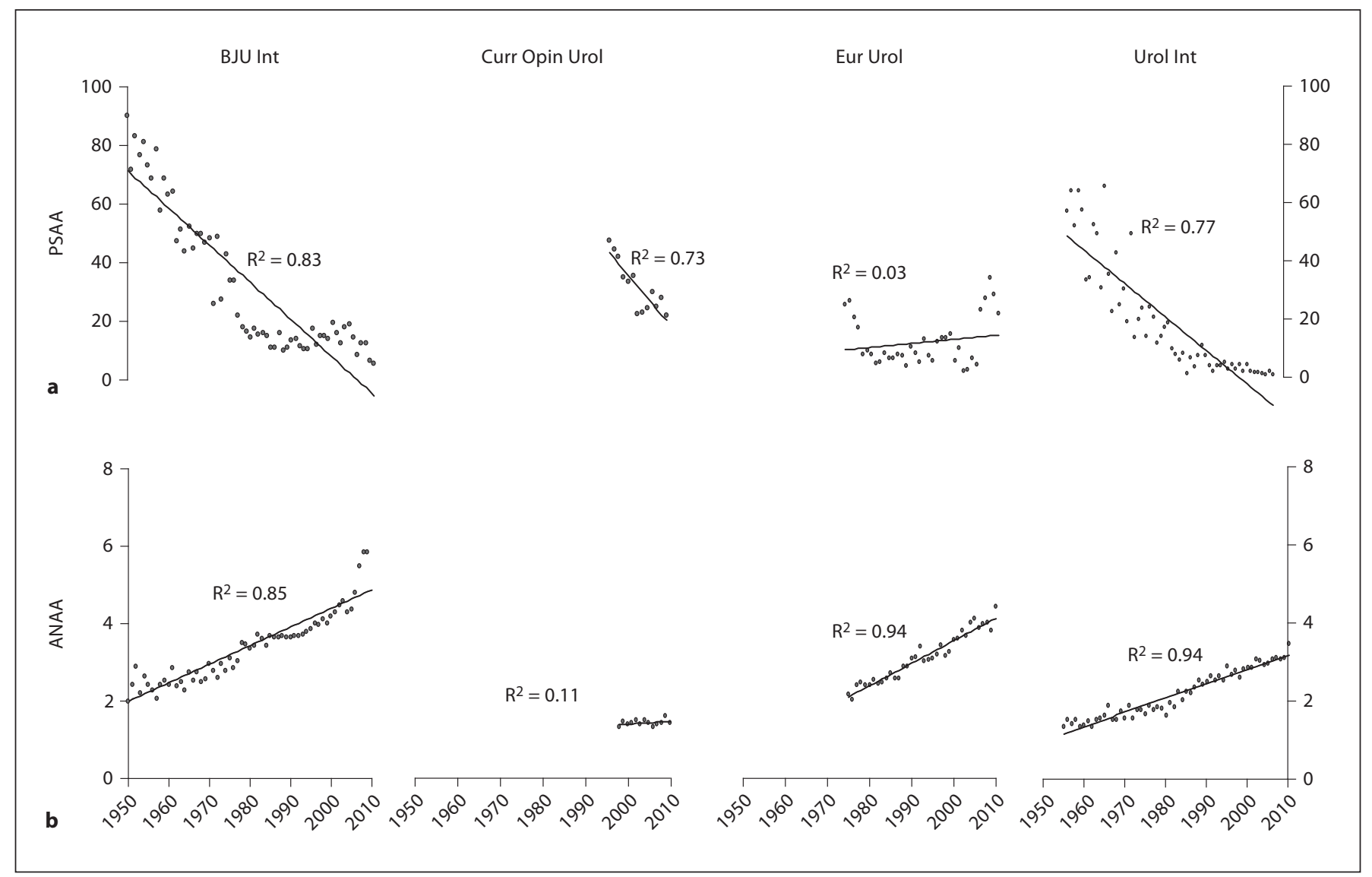

Fig. 1. PSAA (a) and ANAA (b) with the relevant regression lines and $\mathrm{R}^{2}$ value for European journals over the past 6 decades.

As shown in fig. 3 , it was evident that there was a continuous overall increase in the ANAA in both groups. This was mainly due to the increase in the ANAA of original articles and case reports. In the review articles and letters to the editor/editorials the increase was less evident (fig. 4).

The type of article has also changed similarly over time in European and American journals (fig. 5). In the mid-forties of the last century the vast majority of articles were original articles. In the mid- to late fifties, the journals started to publish more case reports and review articles. The maximum percentage of case reports was published between the mid-seventies to the mid-eighties followed by an obvious decline in this type of article. On the other hand, letters to the editor/editorials started to increase since the mid-seventies and reached up to $20 \%$ of the published articles during the last decade.

\section{Discussion}

The results of the current study indicated that there is a trend towards an increase in the ANAA and a decrease in the PSAA among urology journals both in Europe and North America. The increase in the ANAA was mainly due to its increase in the original articles and case reports. In addition, there was no difference in the observed trends between the European and American journals. These results not only apply to the two groups as a whole but also to individual journals. However, there were some exceptions. For example, the PSAA in European Urology did not have a clear-cut decreasing trend. Instead, there was an initial decline similar to the other journals, followed by a period of no obvious change, and lately there has been an increase in the PSAA, unlike other journals. This discrepancy was probably due to the fact that during the past 10 years the percentage of letters to the editor/ 


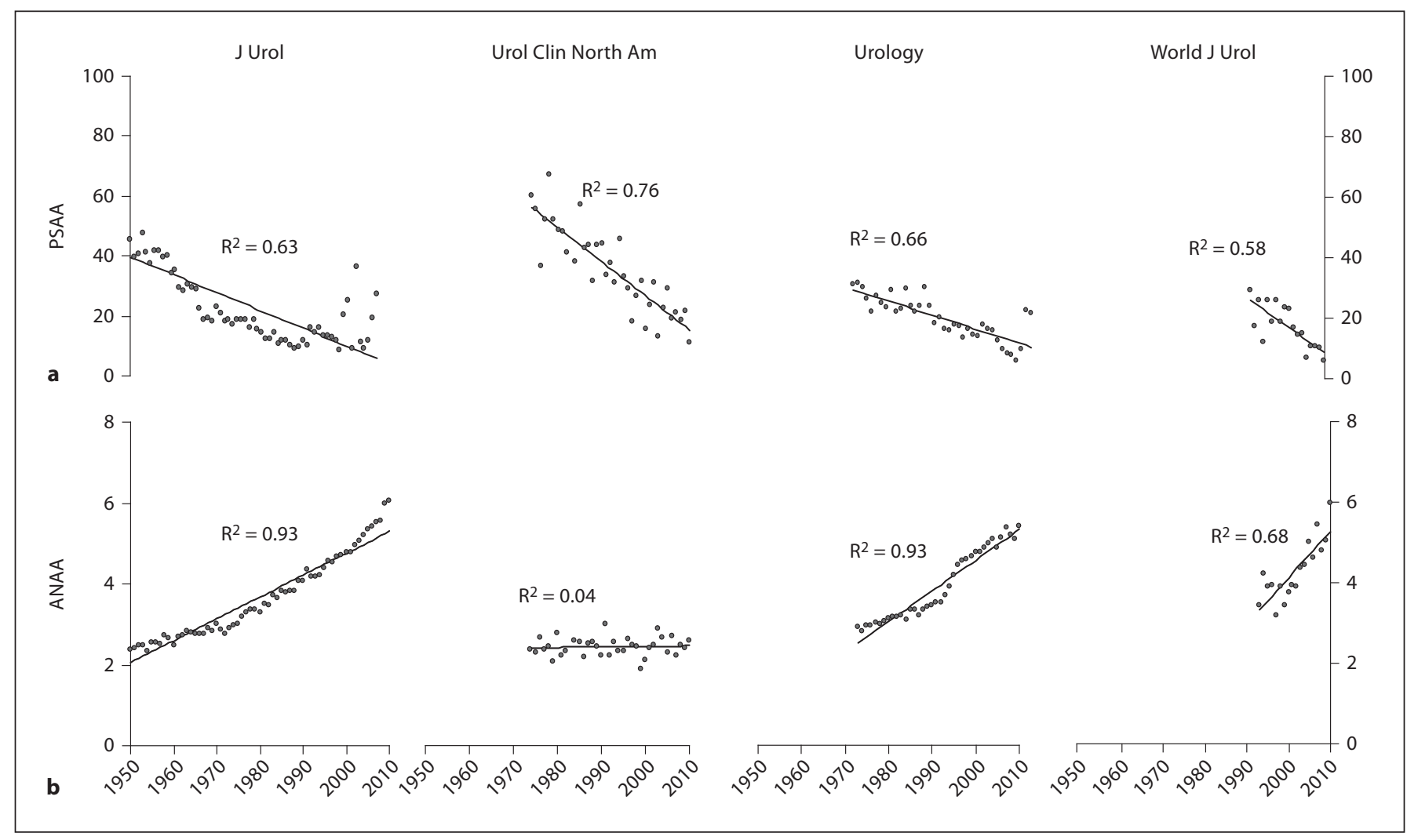

Fig. 2. PSAA (a) and ANAA (b) with the relevant regression lines and $\mathrm{R}^{2}$ value for North American journals over the past 6 decades.

editorials increased dramatically in European Urology. Indeed, during 2008 and 2009, they accounted for up to 48 and $49 \%$ of the total number of articles, respectively. Letters to the editor/editorials tend to have a single author or very few authors, hence explaining the trend in this particular journal.

The ANAA in Urologic Clinics of North America and the Current Opinion in Urology also did not have an obvious increase like the other journals. However, these two journals are predominantly based on review articles which did not show a similar increase in the ANAA like original articles and case reports.

The overall increase in the ANAA or multiple authorship in urology journals was similar to the findings in other clinical disciplines [1-9]. Multiple authorship is a phenomenon which has been observed widely in recent years. The etiology of this phenomenon is multifactorial and is unlikely due to recent change in the definition of authorship, which is defined by most journals as a substantial intellectual contribution to the final draft of the manuscript. The etiology could be classified into one of

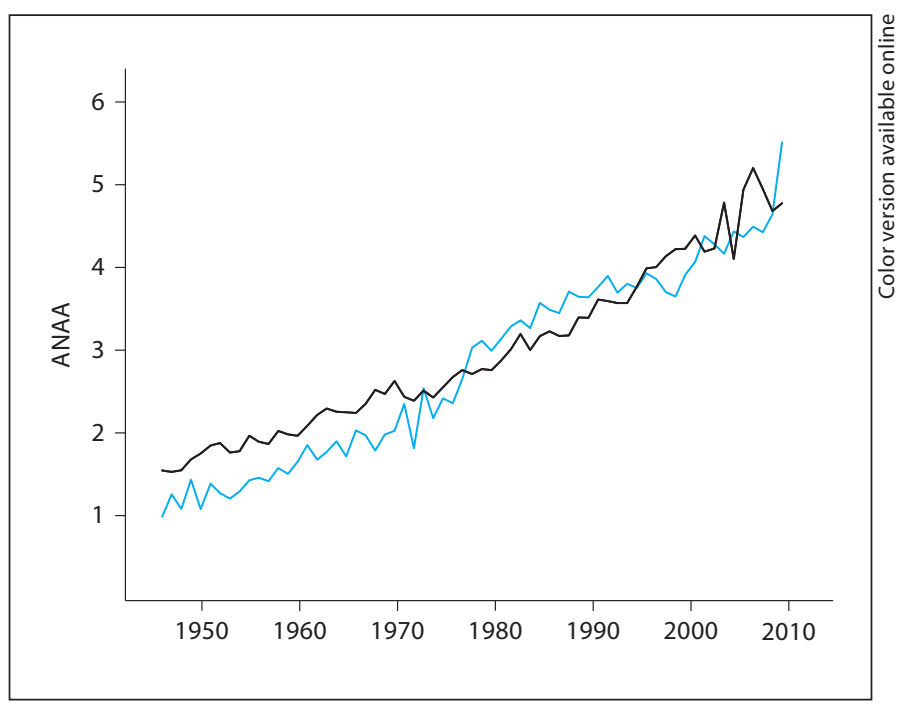

Fig. 3. ANAA in European (grey line, blue in online version) and American journals (black line). 


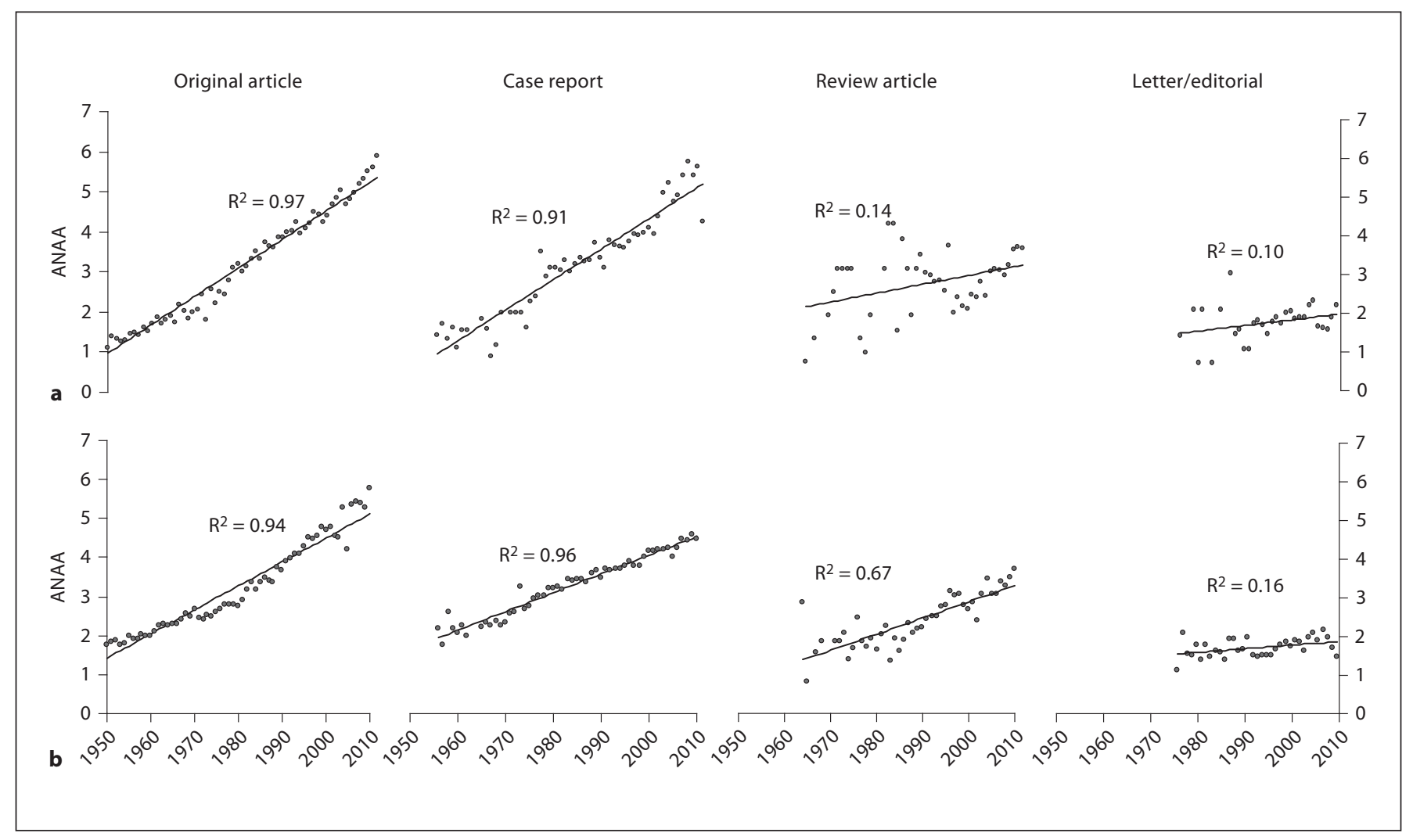

Fig. 4. Change in ANAA for each type of article in European (a) and American (b) journals with the relevant regression lines and $\mathrm{R}^{2}$ value over the past 6 decades.

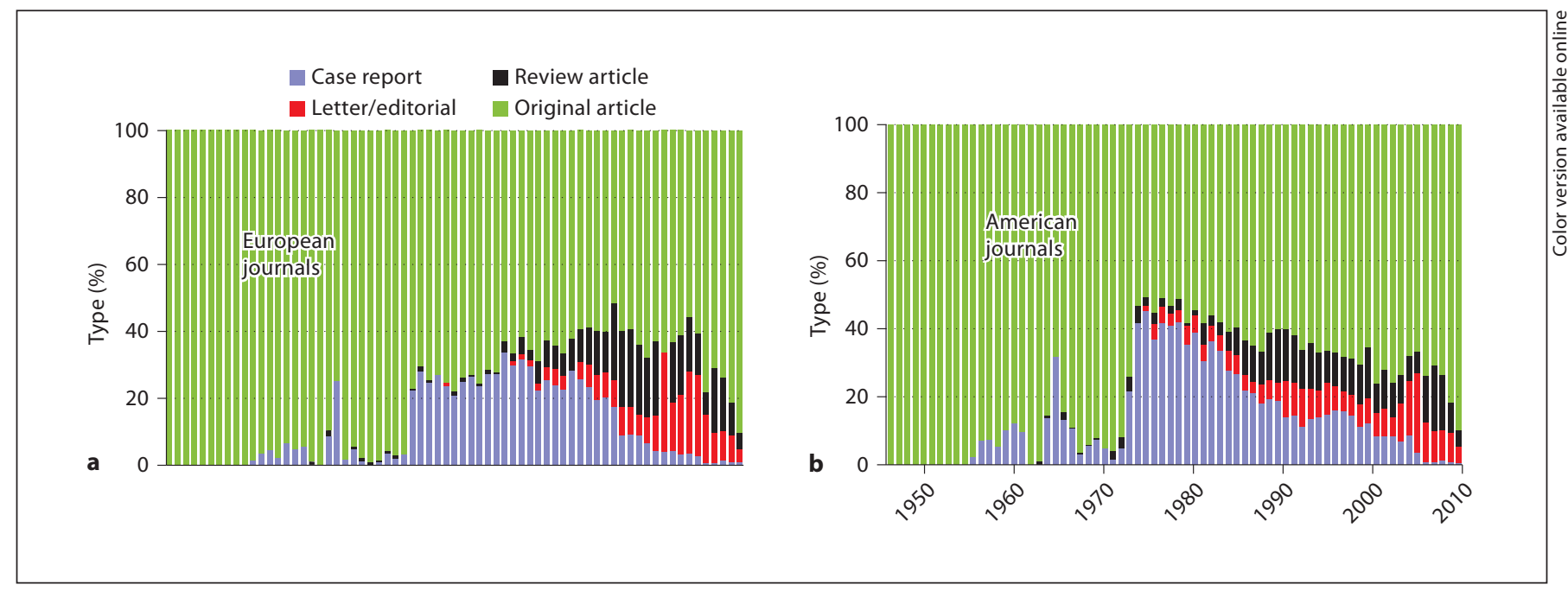

Fig. 5. Percentage of each type of article published over the past 6 decades in European (a) and North American (b) urology journals. 
the following three categories: acceptable or ethical, nonacceptable or non-ethical and debatable reasons. Acceptable reasons for the increase in the ANAA include the increase in the complexity of medical research requiring collaboration between various individuals who bring particular expertise to the research project. Another reason is the increase in the number of multi-institutional projects both at national and international levels due to the recent improvement in communication and technology. Obviously, this internationalization is encouraged because it has resulted in some of the excellent multi-institutional studies [13-15].

The majority of the non-acceptable reasons for multiple authorships are due to the pressure of academia which could be summarized with the phrase 'publish or perish'. This has resulted in the inclusion of 'guest' authors such as senior individuals and chairpersons who did not fulfill the recognized criteria for authorship. Guest authorship may also be practiced by some of the pharmaceutical companies or other institutes in lieu of funding the research project [16].

The justification to include some individuals in the list of authors may be debatable. An example of such individuals are the professional writers who generate the first draft of a manuscript, a practice which may be used in industry to introduce some guest authors $[17,18]$. Although the final manuscript may be totally different from the first draft, some journals believe that it forms the framework for subsequent modifications to justify the inclusion of these writers in the author list [18].

From the current study, it is difficult to ascertain the exact reason for the increase in the ANAA in urology journals, but there is no reason to indicate that these factors are different from those in other medical disciplines. Although the increase in the ANAA in the original articles could be explained by the increase in the complexity and the internationalization of the research, the similar increase in case reports was difficult to explain totally on this basis. Regardless of the exact cause, inappropriate authorship may result in the devaluation of the concept of authorship [10,19] because it credits some individuals for a work which they did not do and could blame others for errors or frauds which they did not commit, thus resulting in difficulties in admitting medical errors and correcting them.

Several solutions have been suggested to decrease the practice of inappropriate authorship. These include increasing the awareness of the scientific community of this problem and its consequences on the credibility of published literature and strict adherence of the journals to the criteria of authorship as per the International Committee of Medical Journal Editors recommendations [20, 21]. Alternatively, authorship could be divided into full authorship for those individuals participating in all research steps from design to the final draft of the manuscript and partial authorship for those who only participate in some steps [22]. More recently, the model of 'contributorship', which implies that authors should decide their individual contributions and disclose these to their readers, has been adopted by many major general medical journals and by the International Committee of Medical Journal Editors as the standard [23-25].

The continuous decrease in publishing case reports in the journals studied in this report might not reflect the overall urology literature as there has been a recent proliferation of electronic and open access journals which continues to publish case reports. Also, some of the case reports might be classified as original articles because sometimes they are considered as case series if more than one case is reported although actually they are just case reports. Nevertheless, the findings of this study apply to the main general urology journals, and if other journals follow the same trend this might deprive the urology literature from an important source of information. Despite the low level of evidence provided by case reports, they may be the only source of information about very rare cases, the management of which could be difficult to find even with randomized controlled trials [26]. Therefore, there might be a need for a journal specializing in publishing interesting urology case reports in an attempt to keep this source of information from vanishing.

This study has some limitations such as the possible inaccuracy of entering article details into PubMed by some journals. Another limitation includes the difficulty in separating editorials from letters to the editor and, therefore, the need to group them together.

\section{Conclusion}

There appeared to be an overall similar increase in ANAA and decrease in PSAA over time in urology journals both in Europe and North America. The changes observed in the ANAA were mainly due to its change in the original articles and case reports. The type of article had also changed over time with a decrease in the percentage of case reports and an increase in the letters to the editor/ editorials. An increase in the awareness of these trends among the urology community might help in guiding towards a better selection policy for articles in urology. 


\section{References}

$>1$ Baranowski T, Cullen KW, Baranowski J: Multiple authorship for community intervention trials. Am J Public Health 1998;88: 827-828.

$>2$ Durani P, Rimouche S, Ross G: 'How many plastic surgeons does it take to write a research article?' - Authorship proliferation in and internationalisation of the plastic surgery literature. J Plast Reconstr Aesthet Surg 2007;60:956-957.

$>3$ Howard MO, Walker RD: Multiple authorship: trends over 50 years in the Journal of Studies on Alcohol. J Stud Alcohol 1996;57: 105-106.

4 King JT Jr: How many neurosurgeons does it take to write a research article? Authorship proliferation in neurosurgical research. Neurosurgery 2000;47:435-440.

$>5$ Mussurakis S: Coauthorship trends in the leading radiological journals. Acta Radiol 1993;34:316-320.

6 Rahman L, Muirhead-Allwood SK: How many orthopedic surgeons does it take to write a research article? 50 years of authorship proliferation in and internationalization of the orthopedic surgery literature. Orthopedics 2010;33:478.

7 Shaban S: Multiple authorship trends in prestigious journals from 1950 to 2005. Saudi Med J 2007;28:927-932.

$>8$ Shaban S, Aw TC: Trend towards multiple authorship in occupational medicine journals. J Occup Med Toxicol 2009;4:3. $\checkmark 9$ Weeks WB, Wallace AE, Kimberly BC: Changes in authorship patterns in prestigious US medical journals. Soc Sci Med 2004;59:1949-1954.

10 Rennie D: Who did what? Authorship and contribution in 2001. Muscle Nerve 2001;24: 1274-1277.

11 PubMed. http://www.ncbi.nlm.nih.gov/ PubMed.

12 ISI Web of Knowledge. http://admin. isiknowledge.com.

13 Schroder FH, Hugosson J, Roobol MJ, Tammela TL, Ciatto S, Nelen V, Kwiatkowski M, Lujan M, Lilja H, Zappa M, et al: Screening and prostate cancer mortality in a randomized European study. N Engl J Med 2009;360: 1320-1328.

$>14$ Bill-Axelson A, Holmberg L, Ruutu M, Haggman M, Andersson SO, Bratell S, Spangberg A, Busch C, Nordling S, Garmo $\mathrm{H}$, et al: Radical prostatectomy versus watchful waiting in early prostate cancer. $\mathrm{N}$ Engl J Med 2005;352:1977-1984.

15 Wendt-Nordahl G, Rotert H, Trojan L, Michel MS, Peters CR, Alken P, Knoll T: Intravenous contrast media in uroradiology: evaluation of safety and tolerability in almost 50,000 patients. Med Princ Pract 2006;15: 358-361.

16 Schott G, Pachl H, Limbach U, Gundert-Remy U, Lieb K, Ludwig WD: The financing of drug trials by pharmaceutical companies and its consequences: part 2: a qualitative, systematic review of the literature on possible influences on authorship, access to trial data, and trial registration and publication. Dtsch Arztebl Int 2010;107:295-301.
17 Hirsch LJ: Conflicts of interest, authorship, and disclosures in industry-related scientific publications: the tort bar and editorial oversight of medical journals. Mayo Clin Proc 2009;84:811-821.

18 Baskin PK, Knopman DS, Gross RA: Conflicts of interest, authorship, and disclosures in industry-related scientific publications. Mayo Clin Proc 2010;85:196-197; author 201-204.

19 Kennedy D: Multiple authors, multiple problems. Science 2003;301:733.

20 International Committee of Medical Journal Editors: Uniform Requirements for Manuscripts Submitted to Biomedical Journals: Writing and Editing for Biomedical Publication. http://www.icmje.org/urm_full.pdf. 2010.

21 Lazar R: Up for grabs - authors are a dime a dozen: the problem of multiple authors. Acta Paediatr 2004;93:589-591.

22 Schechter AN, Wyngaarden JB, Edsall JT, Maddox J, Relman AS, Angell M, Stewart WW: Colloquium on scientific authorship: rights and responsibilities. Faseb J 1989;3: 209-217.

23 Rennie D: Integrity in scientific publishing. Health Serv Res 2010;45:885-896.

24 Rennie D, Flanagin A, Yank V: The contributions of authors. Jama 2000;284:89-91.

25 Yank V, Rennie D: Disclosure of researcher contributions: a study of original research articles in The Lancet. Ann Intern Med 1999; 130:661-670

26 Mant D: Can randomised trials inform clinical decisions about individual patients? Lancet 1999;353:743-746. 